ARTICLE

\title{
Anti-thymocyte globulin with CsA and MMF as GVHD prophylaxis in nonmyeloablative HLA-mismatched allogeneic
} HCT

Walter J. F. M. van der Velden ${ }^{1 凶}{ }^{凶}$, Goda Choi ${ }^{2}$, Moniek A. de Witte ${ }^{3}$, Arnold van der Meer ${ }^{4}$, Anton F. J. de Haan ${ }^{5}$, Nicole M. A. Blijlevens ${ }^{1}$, Gerwin Huls ${ }^{2}$, Jürgen Kuball (iD ${ }^{3}$ and Suzanne van Dorp ${ }^{1}$

(c) The Author(s), under exclusive licence to Springer Nature Limited 2021

Nonmyeloablative regimens are used for allogeneic hematopoietic cell transplantation (HCT) of older or medically unfit patients, but successful outcome is still hindered by graft-versus-host disease (GVHD), especially in the setting of HLA-mismatched HCT. New GVHD prophylaxis strategies are emerging, including the triple drug strategy, that improve the GVHD-free and relapse-free survival (GRFS). Because the impact of ATG in HLA-mismatched Flu-TBI-based nonmyeloablative HCT has not been investigated, we did a retrospective analysis in three Dutch centers. 67 patients were evaluable, with a median age of 56 years. Overall survival, relapsefree survival and GRFS at 4 years were $52 \%, 43 \%$, and 38\%, respectively. NRM findings and cumulative incidence of relapse at 4 years were $26 \%$ and $31 \%$, respectively. At 1 -year grade II-IV had occurred in $40 \%$ of the patients, and the incidence of moderatesevere chronic GVHD incidence was $16 \%$. Acknowledging the limitations of retrospective analyses, we conclude that the use of ATG for HLA-mismatched truly nonmyeloablative Flu-TBI HCT is feasible and results in acceptable long term outcomes, especially with regards to GRFS. We consider ATG in combination with cyclosporin and mycophenolate mofetil as an alternative for the triple drug strategy that uses sirolimus for GVHD prophylaxis in this particular setting.

Bone Marrow Transplantation (2021) 56:2651-2655; https://doi.org/10.1038/s41409-021-01369-9

\section{INTRODUCTION}

Nonmyeloablative regimens are successfully used for allogeneic hematopoietic cell transplantation (HCT) of older or medically unfit patients [1]. Nevertheless graft-versus-host disease (GVHD) and disease relapse remain the main obstacles whose impact is reflected in the composite endpoint GVHD-free, relapse-free survival (GRFS) [2]. Whilst Flu-TBI-based HCT with HLA-matched related and unrelated donors results in a GRFS of $\sim 30 \%$ at 3-years, results are probably worse with HLA-mismatched donors [3]. Recently, two studies from the Fred Hutchinson Cancer Research Center in Seattle showed that adding sirolimus to the standard GVHD prophylaxis regimen, consisting of cyclosporine $A(C s A)$ and mycophenolate mofetil (MMF) (triple drug strategy), resulted in less acute GVHD and better survival, when using HLA-matched or mismatched unrelated donor [4,5].

Other means to improve GVHD prophylaxis are amongst others ex vivo T-cell depletion, in vivo T-cell depletion with antithymocyte globulin (ATG), and post-transplant cyclophosphamide. ATG is effective in diminishing acute and chronic GVHD and is considered the standard of care in the setting of HLA-matched and mismatched unrelated donor $\mathrm{HCT}$, especially in the setting of myeloablative conditioning [6]. However, in the setting of nonmyeloablative and reduced-intensity (RIC) conditioning the reduced GVHD incidence with ATG must be weighed against an increased risk for disease relapse [6]. Because the impact of ATG in HLA-mismatched truly nonmyeloablative HCT has not been systematically investigated, we did a retrospective analysis to determine the transplant outcomes when using ATG for GVHD prophylaxis in this particular setting.

\section{METHODS \\ Study design and participants \\ We performed a retrospective analysis in three Dutch HCT centers. Patients receiving anti-thymocyte (ATG) in combination with Flu-TBI as nonmye- loablative conditioning for HCT with a HLA-mismatched unrelated donor (MMUD) were included. Nonmyeloablative condition was chosen because of high age ( $\geq 55$ years, later 60 years) or a high HCT comorbidity index (HCT-Cl 3 or higher). Only patients with a follow-up of at least 6 months and HCT for a hematologic malignancy were included. We identified 79 patients that received ATG-Flu-TBI conditioning mostly from a MMUD. Twelve patients were excluded because of a follow-up less than 6 months $(n=2)$, missing data ( $n=8$; lost to follow-up and incomplete records) and HCT for aplastic anemia $(n=2)$, leaving 67 patients. The characteristics and features of the patients, donors, and HCT procedures are summarized in Table 1. \\ This retrospective study was approved by the Institutional Review Board at the Radboud University Nijmegen Medical Center.}

\footnotetext{
${ }^{1}$ Department of Hematology, Radboud University Medical Center, Nijmegen, The Netherlands. ${ }^{2}$ Department of Hematology, University Medical Center Groningen, University of

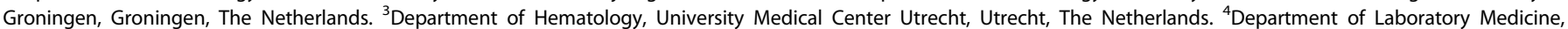
Radboud University Medical Center, Nijmegen, The Netherlands. ${ }^{5}$ Department for Health Evidence, Radboud University Medical Center, Nijmegen, The Netherlands. email: Walter.vanderVelden@Radboudumc.nl
} 
Table 1. Patient, donor, and HCT characteristics.

\begin{tabular}{|c|c|}
\hline Characteristic & Value \\
\hline Patient age, median (IQR), years & $56(50-64)$ \\
\hline Male sex, no (\%) & $36(54 \%)$ \\
\hline Donor age, median (IQR), years & $34(25-44)$ \\
\hline Unrelated donor, no. (\%) & $66(99 \%)$ \\
\hline Decitabine, no. (\%) & $12(18 \%)$ \\
\hline \multicolumn{2}{|l|}{ Stem cell source, no. (\%) } \\
\hline PBSC & $67(100 \%)$ \\
\hline \multicolumn{2}{|l|}{ HLA-match, no. (\%) } \\
\hline 9/10 (one locus mismatch) & $65(97 \%)$ \\
\hline $8 / 10$ (two locus mismatch) $^{a}$ & $2(3 \%)$ \\
\hline HLA class I mismatch, no. (\%) & 50 \\
\hline HLA-A & $23(46 \%)$ \\
\hline HLA-B & $10(20 \%)$ \\
\hline HLA-C & $17(34 \%)$ \\
\hline HLA class II mismatch, no. (\%) & 19 \\
\hline HLA-DRB1 & $12(70 \%)$ \\
\hline HLA-DBQB1 & $7(30 \%)$ \\
\hline \multicolumn{2}{|l|}{ Sex of patient/donor, no. (\%) } \\
\hline Male/female & $10(15 \%)$ \\
\hline Other & $55(82 \%)$ \\
\hline Missing & $2(3 \%)$ \\
\hline \multicolumn{2}{|l|}{ Diagnoses, no. (\%) } \\
\hline Acute myeloid leukemia & $28(42 \%)$ \\
\hline Myelodysplastic syndrome & $13(19 \%)$ \\
\hline MDS-EB1 & $5(7 \%)$ \\
\hline MDS-EB2 & $6(9 \%)$ \\
\hline Other & $2(3 \%)$ \\
\hline Chronic myelomonocytic leukemia & $2(3 \%)$ \\
\hline CML-BP/MPN-BP & $2(3 \%)$ \\
\hline Chronic myeloid leukemia & $1(2 \%)$ \\
\hline Acute lymphoblastic leukemia & $6(9 \%)$ \\
\hline Non-Hodgkin lymphoma & $5(7 \%)$ \\
\hline Chronic Iymphocytic leukemia & $4(6 \%)$ \\
\hline Hodgkin lymphoma & $1(2 \%)$ \\
\hline Multiple myeloma & $4(6 \%)$ \\
\hline \multicolumn{2}{|l|}{ Disease status at $\mathrm{HCT}$} \\
\hline CR1 & 39 \\
\hline CR2 & 8 \\
\hline CR3 & 2 \\
\hline$P R$ & 4 \\
\hline Untreated MDS/CMML & 8 \\
\hline Missing & 6 \\
\hline \multicolumn{2}{|l|}{ Disease risk index, no. (\%) } \\
\hline Low & $6(9 \%)$ \\
\hline Intermediate & $32(48 \%)$ \\
\hline High/very-high & $29(43 \%)$ \\
\hline \multicolumn{2}{|l|}{ ELN2017 risk (AML) } \\
\hline Intermediate & $15(54 \%)$ \\
\hline Adverse & $13(46 \%)$ \\
\hline \multicolumn{2}{|l|}{ HCT comorbidity index, no. (\%) } \\
\hline 0 & $12(18 \%)$ \\
\hline $1-2$ & $23(34 \%)$ \\
\hline $3+$ & $28(42 \%)$ \\
\hline Missing & $4(6 \%)$ \\
\hline \multicolumn{2}{|l|}{ HCT year, no. (\%) } \\
\hline 2009-12 & $24(36 \%)$ \\
\hline $2013-6$ & $30(45 \%)$ \\
\hline 2017-20 & $13(19 \%)$ \\
\hline
\end{tabular}

${ }^{\mathrm{a}}$ Two patients had a two locus class I mismatch; one HLA-A and HLA-C and one HLA-B and HLA-C.

\section{Conditioning and post HCT immunosuppression}

Conditioning consisted of fludarabine $30 \mathrm{mg} / \mathrm{m}^{2}$ fludarabine on days -4 , -3 , and -2 , and low-dose TBI ( 2 Gy) on day -1 (days are expressed relative to transplantation) [7, 8]. In vivo T-cell depletion was performed with $2 \mathrm{mg} / \mathrm{kg} /$ day Thymoglobulin (rabbit-ATG; Genzyme) on days $-8,-7$, -6 , and -5 . Some patients participated in a HCT study for adverse risk myeloid malignancies and received 10 days of decitabine $\left(20 \mathrm{mg} / \mathrm{m}^{2}\right)$ (NCT02252107) [9]. On day 0, all patients received a T-cell-repleted graft with mobilized peripheral blood stem cells. Post-HCT immunosuppression included MMF for 96 days and oral CsA for 180 days. CsA started at day -3 and was initially dosed at $4.5 \mathrm{mg} / \mathrm{kg}$ twice daily, with tapering starting on day $+100[10]$.

\section{HLA typing}

Patients and donors were typed for HLA-A, B, C, DRB1, DR3/4/5, DQB1, and DPB1. Typing for class I was based on full gene sequencing and typing of class II was based on sequencing of exons 2 and 3. Matching was based on HLA-A, B, C, DRB1, and DQB1 at the second field level.

\section{Definitions}

Non-relapse mortality (NRM), cumulative incidence of relapse (CIR), relapsefree survival (RFS), and OS were defined according to standard criteria [11]. GRFS was defined as surviving post HCT without relapse and without severe acute GVHD (i.e. grade III-IV) and/or severe chronic GVHD [2]. Survival outcomes were analysed at 1 and 4 years post HCT. Acute and chronic GVHD were diagnosed and graded as proposed by Harris et al. and Jagasia et al. [12, 13]. Incidence of acute GVHD was determined at 100 and 180 days; the latter was chosen because with the use of Flu-TBI-based conditioning acute GVHD occurs beyond day 100 in a considerable proportion of patients $[10,14]$. The incidence of EBV and CMV infection and disease was defined in accordance with established guidelines $[15,16]$. The disease risk index (DRI), $\mathrm{HCT}-\mathrm{Cl}$, and European Group for Blood and Marrow Transplantation (EBMT) risk score were determined in accordance with published scoring systems [17-19].

\section{Statistics}

We used descriptive statistics to analyze the patient, donor, and HCT characteristics. The Kaplan-Meier method was used to estimate OS, RFS, and GRFS. A competing risk analysis was performed to obtain CIR estimates with NRM as a competing risk and vice versa [11]. Putative factors affecting severe acute GVHD, CIR, NRM, and OS were selected for univariate analysis. Considering the small cohort with a limited number of events only factors with a $P$ value $<0.2$ were incorporated in a multivariate analysis using logistic regression or Cox regression. Analyses were done with SAS ${ }^{\circ} 9.4$ and IBM SPSS Statistics 25. Differences with a $P$ value of $<0.05$ were considered statistically significant.

\section{RESULTS}

Between 2010 and $202067(n=67)$ patients received ATG-Flu-TBI conditioning for a HLA-mismatched unrelated donor allogeneic HCT. The median age was 56 years (range 30-75) and 54\% were male. Most patients were transplanted for a myeloid malignancy; 43 (64\%) diagnosed with AML, MDS with excess blasts (MDS-EB1/ 2), CMML with $\geq 5 \%$ marrow blasts (CMML1/2), or blast phase MPN or CML (Table 1). DRI was high or very high in $43 \%$ and $46 \%$ of AML patients had adverse genetics according to the ELN2017 risk classification. The median HCT-Cl and EBMT score were 2 (range $0-7$, missing $n=4$ ) and 3 (range 0-7, missing $n=2$ ). 46 (69\%) patients had a single HLA class I antigen mismatch, 2 (3\%) had two HLA class antigen mismatches, and 19 (28\%) patients were mismatched for HLA class II. Unmodified PBSC grafts were obtained only from unrelated donors.

\section{Post HCT outcome}

The median follow-up of surviving patients was 57 months (range 10-116). Overall survival at 4 years was $52 \%(95 \% \mathrm{Cl} 40-62)$, Fig. 1. RFS and GRFS at the same time point were $43 \%(95 \% \mathrm{Cl} 31-55)$ and $38 \%(95 \% \mathrm{Cl} 26-49)$, respectively, Fig. 1. NRM findings at 1 


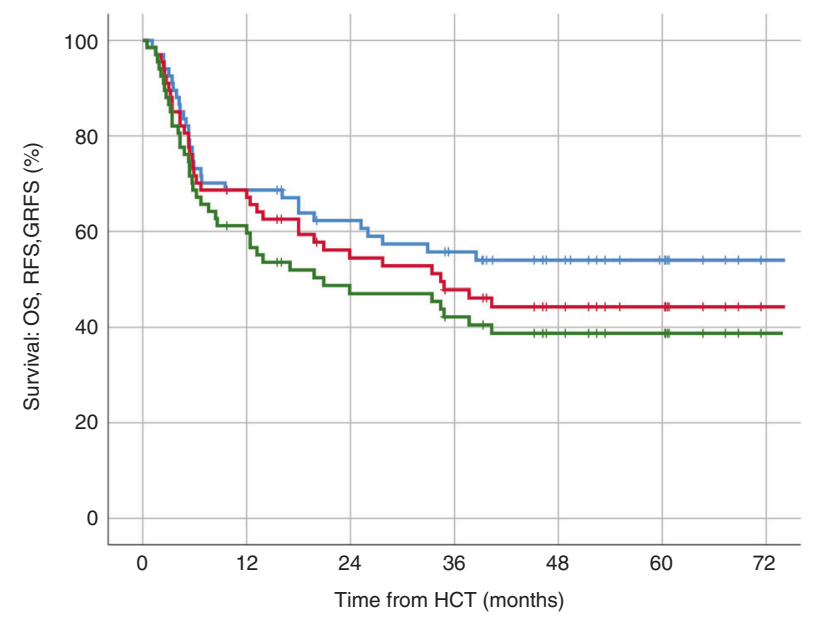

Fig. 1 Survival outcomes HLA-mismatched HCT after ATG-Flu-TBI conditioning $(n=67)$. Kaplan-Meier curves of overall survival (blue), relapse-free survival (red-curve) and GVHD-free, relapse-free survival (green curve).

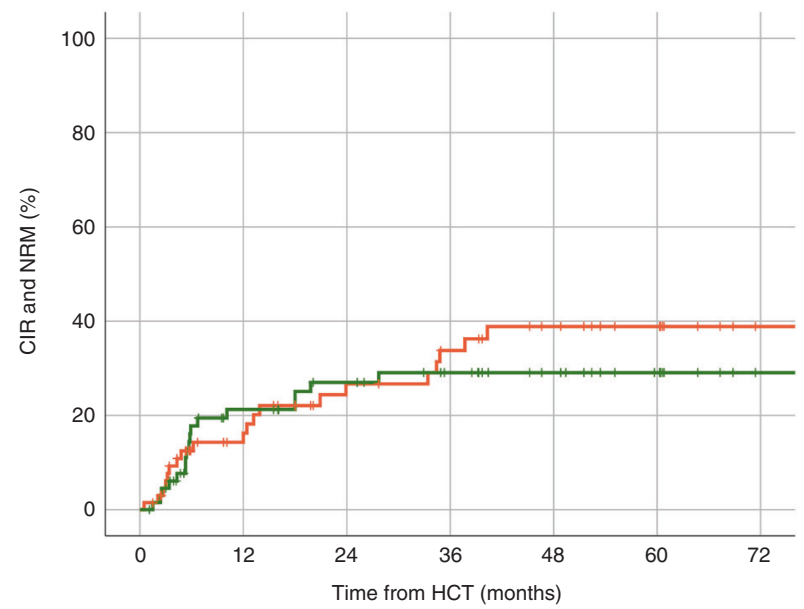

Fig. 2 Incidence of relapse and non-relapse mortality. Cumulative incidence of relapse (orange) and non-relapse mortality (green), $n=67$.

and 4 years were $20 \%(95 \% \mathrm{Cl} 12-27)$ and $26 \%(95 \% \mathrm{Cl} 16-37)$, respectively, Fig. 2. CIR at 1 and 4 years were $16 \%(95 \% \mathrm{Cl} 6-27)$ and $31 \%$ (95\% Cl 20-43), respectively, Fig. 2.

Median PBSC CD34 + cell dose was $7.9 \times 10^{6} / \mathrm{kg}$ (IQR 6.2-10.2). Of the 48 patients developing neutropenia the median time to neutrophil and thrombocyte recovery was 17 days (IQR 13-22) and 16 days (IQR 14-19), respectively. Sustained engraftment was achieved in all but two (3\%) patients. One case of primary graft failure was probably related to cryopreservation (COVID-19 policy) and re-HCT was not successful. The other case was a rejection related to a HLA-C mismatch in the host-versus-graft direction.

In multivariate analysis significant factors for NRM and relapse were identified, being HLA class I mismatch for NRM $(P=0.01)$ and DRI high/very high for relapse $(P=0.01)$, Supplementary Table. Class I mismatch was also significantly related to OS $(P=0.01)$ and DRI showed a trend for OS $(P=0.07)$, Supplementary Table.

\section{Graft-versus-host disease and infectious complications}

The cumulative incidence of grade II-IV and severe acute GVHD at day 100 and 180 days were, $27 \%(95 \% \mathrm{Cl} 17-38)$ and $38 \%(95 \% \mathrm{Cl}$ $28-51 \%)$ and $7 \%(95 \% \mathrm{Cl} 2-16)$ and $11 \%(95 \% \mathrm{Cl} 5-22)$, respectively, Fig. 3. The incidence of grade II-IV was comparable for HLA class I and II mismatches; e.g. grade II-IV 39.6\% versus $36.8 \%(P=0.57)$. However, severe acute GVHD occurred only in

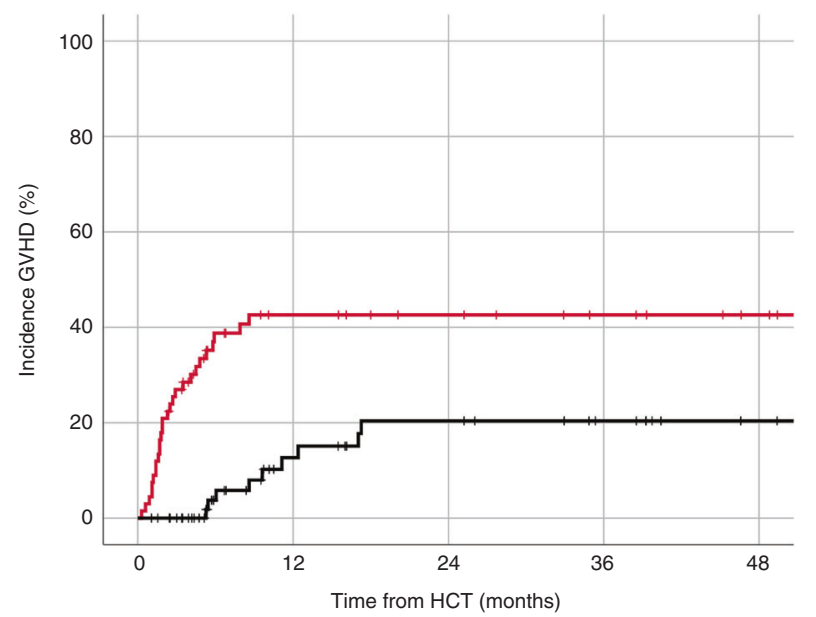

Fig. 3 Incidence of graft-versus-host disease. Cumulative incidence of acute GVHD grade II-IV (red) and moderate-severe chronic GVHD (black).

HLA class I mismatched patients (12\%). In multivariate analysis HLA class I mismatch was the only significant factor for severe acute GVHD $(P=0.02)$.

The cumulative incidence of chronic GVHD and moderatesevere chronic GVHD at 1 year was $26 \%(95 \% \mathrm{Cl} 15-37)$ and $16 \%$ $(95 \% \mathrm{Cl} 9-27)$ and at 4 years $30 \%(95 \% \mathrm{Cl} ; 21-42)$ and $18 \%(95 \%$ $\mathrm{Cl} ; 10-29)$, Fig. 3. No significant difference in moderate-severe chronic GVHD was seen between HLA class I and II mismatches (14.5\% vs $10.5 \%, P=0.62$ ).

\section{Infectious complications}

Data on CMV and EBV were available for 64 (96\%) and 62 (93\%) patients, respectively. Of the $40 \mathrm{CMV}$ positive HCT recipients 16 (40\%) experienced a CMV reactivation with two of them progressing to CMV disease (5\%; pneumonitis, enteritis). EBV infection occurred in 14 patients (22\%) with two cases of EBV disease; one probable and one proven PTLD. No CMV-related mortality occurred, and EBV disease resulted in one death.

\section{DISCUSSION}

In this retrospective analysis we provide data on the use of ATG added to CsA and MMF in HLA-mismatched truly nonmyeloablative HCT. We show that this GVHD prophylaxis regimen was feasible and effective with acceptable rates of GVHD and longterm outcomes with an OS at 4 years of $52 \%$ comparable to outcomes reported on alternative donor HCT in larger registries [20]. Especially, considering the high risk setting, with $43 \%$ high/ very high DRI and a considerable number of patients with advanced myeloid malignancies. Also the relapse rate was not higher than expected in this high-risk population, a concern often expressed with the use of ATG. Also the rate of graft failure of $3 \%$ was low. The GRFS of $38 \%$ at 4 years also seems comparable to outcomes published on HCT with alternative donors and even superior to HLA-mismatched RIC and MAC HCT with use of serotherapy [21]. One drawback, clearly, was the higher incidence of viral complications including proven EBV disease and CMV disease, although with low attributable mortality. The main risk factors for OS in multivariate analysis were DRI and presence of a HLA class I mismatch. The impact of DRI on OS was not surprising, and mainly due to the very poor outcome of patients with a veryhigh DRI; none of 6 surviving. The impact of HLA class I mismatch on OS was mainly related to the higher incidence of severe GVHD with the associated NRM. The biological significance of HLA class I mismatches with a higher rate of severe acute GVHD has been repeatedly confirmed in large cohorts [22]. 
Our outcomes can compete to those recently reported from the prospective phase II study by Kornblit et al. who used a triple drug strategy with sirolimus in addition to CsA and MMF in the same setting of Flu-TBI based conditioning [4]. Relapse incidence, CMV infections, and incidence of grade II-IV were comparable, but with ATG the incidence of chronic GVHD was lower (30\% versus $57 \%$ ) and severe acute GVHD higher (11\% versus $1 \%)$. The NRM was lower and OS was better in the Seattle cohort, however there were several important differences with regards to underlying diagnosis (AML/ALL; $51 \%$ vs $34 \%$ ) and DRI (high/very-high; $43 \%$ vs $24 \%$ ). Unfortunately, GRFS and EBV infections were not reported, and could not be compared.

In general, the possible higher risk for relapse with the use of ATG and delayed graft-versus-leukemia effects due to in vivo T-cell depletion cannot be neglected [23]. However, in our cohort, ATG was given relatively early (start day -8 ), reducing the in vivo exposure to ATG, thereby mitigating the depletion effect on donor lymphocytes but not patient lymphocytes. Optimal dosing of ATG is complex, but starting day -8 positively impacts overall survival in the MUD setting, at least partially because of enhanced immune recovery [24]. Unfortunately, we have no immune reconstitution data available substantiating this assumption in this study. Nevertheless, in the setting of NMA and RIC conditioning as mentioned in the introduction the reduced GVHD incidence with ATG must be weighed against an increased risk for disease relapse [6]. Worth mentioning in this regard is recent study showing that even in a high risk AML setting with RIC conditioning there was no adverse effect of ATG on relapse incidence [25]. In addition, in large randomized phase 3 trials ATG did not have an impact on relapse incidence either with the use of MAC or NMA/RIC conditioning $[26,27]$.

Acknowledging the limitations of such comparisons in our opinion serotherapy with ATG can be an alternative to sirolimus when added to CSA and MMF for Flu-TBI-based nonmyeloablative conditioning. The ease of ATG can be an advantage, as the use of sirolimus requires experience, meticulous therapeutic drug monitoring, and when combined with CsA, alertness for endothelial-related complications such as transplant-associated thrombotic microangiopathy and sinusoidal obstruction syndrome $[28,29]$. The main drawback of ATG remains an increased infections risk, but we had only limited data on bacterial and fungal infections. The high incidence of CMV and EBV infections and occasionally disease should not be underestimated with institution of screening and preventive measures. Fortunately, these infections can nowadays be managed better by pre-emptive rituximab strategies and use of letermovir for CMV prophylaxis. In this context it is worth mentioning that introducing letermovir in the triple drug strategy might pose a problem, because there are significant drug-drug interactions with both calcineurin inhibitors and sirolimus [30]. Recently the role of post-transplantation cyclophosphamide (ptCy) used for GVHD prophylaxis has gained much attention and is already widely applied in the clinic. Recently, a large study in AML patients showed superiority of ptCy over ATG in the HLA-mismatched setting with a better OS mainly due to less acute GVHD while there was no difference in relapse incidence [31]. This novel approach could therefore possibly become a third option, although, currently, in the Flu-TBI NMA setting, no data are available.

Strengths of this study are the fact that, to our knowledge, no data exist on the use of ATG in the Flu-TBI HCT setting. In a multicenter design we included a significant number of patients with data on important survival outcomes and GVHD. Limitations include obviously the retrospective nature of the study, missing data (e.g. with regards to performance status, immune reconstitution, bacterial and fungal infections), a modest statistical analysis, and the study period spanning 11 years.

Acknowledging the mentioned limitations, we conclude that the use of ATG for HLA-mismatched nonmyeloablative Flu-TBI HCT is feasible and results in acceptable long term outcomes, especially with regards to GRFS and chronic GVHD incidence. We believe that ATG can be considered a reasonable alternative for the triple drug strategy that was recently published [4], especially for centers with limited experience with sirolimus or those unable to perform therapeutic drug monitoring that is required for safe use in the light of complex drug-drug interactions.

\section{REFERENCES}

1. Storb R, Sandmaier BM. Nonmyeloablative allogeneic hematopoietic cell transplantation. Haematologica. 2016;101:521-30. https://doi.org/10.3324/ haematol.2015.132860.

2. Ruggeri A, Labopin M, Ciceri F, Mohty M, Nagler A. Definition of GvHD-free, relapse-free survival for registry-based studies: an ALWP-EBMT analysis on patients with AML in remission. Bone marrow Transplant. 2016;51:610-1. https://doi.org/10.1038/bmt.2015.305.

3. Heinicke T, Labopin M, Polge E, Niederwieser D, Platzbecker U, Sengelov H, et al. Fludarabine/busulfan versus fludarabine/total-body-irradiation (2 Gy) as conditioning prior to allogeneic stem cell transplantation in patients ( $>/=60$ years) with acute myelogenous leukemia: a study of the acute leukemia working party of the EBMT. Bone marrow Transplant. 2020;55:729-39. https://doi.org/10.1038/ s41409-019-0720-0.

4. Kornblit B, Storer BE, Andersen NS, Maris MB, Chauncey TR, Petersdorf EW, et al. Sirolimus with CSP and MMF as GVHD prophylaxis for allogeneic transplantation with HLA antigen-mismatched donors. Blood. 2020;136:1499-506. https://doi. org/10.1182/blood.2020005338.

5. Sandmaier BM, Kornblit B, Storer BE, Olesen G, Maris MB, Langston AA, et al. Addition of sirolimus to standard cyclosporine plus mycophenolate mofetil-based graft-versus-host disease prophylaxis for patients after unrelated nonmyeloablative haemopoietic stem cell transplantation: a multicentre, randomised, phase 3 trial. Lancet Haematol. 2019;6:e409-e418. https://doi.org/10.1016/ S2352-3026(19)30088-2.

6. Bonifazi F, Rubio MT, Bacigalupo A, Boelens JJ, Finke J, Greinix H, et al. Rabbit ATG/ATLG in preventing graft-versus-host disease after allogeneic stem cell transplantation: consensus-based recommendations by an international expert panel. Bone marrow Transplant. 2020;55:1093-102. https://doi.org/10.1038/ s41409-020-0792-x.

7. Sorror ML, Sandmaier BM, Storer BE, Franke GN, Laport GG, Chauncey TR, et al. Long-term outcomes among older patients following nonmyeloablative conditioning and allogeneic hematopoietic cell transplantation for advanced hematologic malignancies. JAMA: J Am Med Assoc. 2011;306:1874-83. https://doi.org/10.1001/jama.2011.1558.

8. Storb R, Gyurkocza B, Storer BE, Maloney DG, Sorror ML, Mielcarek M. et al. Allogeneic hematopoietic cell transplantation following minimal intensity conditioning: predicting acute graft-versus-host disease and graft-versus-tumor effects. Biol Blood Marrow Transpl. 2013;19:792-8. https://doi.org/10.1016/j. bbmt.2013.02.006.

9. Cruijsen M, Hobo W, van der Velden WJ, Bremmers ME, Woestenenk R, Bar B. et al. Addition of 10-day decitabine to fludarabine/total body irradiation conditioning is feasible and induces tumor-associated antigen-specific $T$ cell responses. Biol Blood Marrow Transpl. 2016;22:1000-8. https://doi.org/10.1016/j. bbmt.2016.02.003.

10. de Kort EA, de Lil HS, Bremmers MEJ, van Groningen LFJ, Blijlevens NMA, Huls G, et al. Cyclosporine $A$ trough concentrations are associated with acute GvHD after non-myeloablative allogeneic hematopoietic cell transplantation. PLoS One. 2019;14:e0213913 https://doi.org/10.1371/journal.pone.0213913.

11. lacobelli $\mathrm{S}$, Committee ES. Suggestions on the use of statistical methodologies in studies of the European Group for Blood and Marrow Transplantation. Bone marrow Transplant. 2013;48:S1-37. https://doi.org/10.1038/bmt.2012.282.

12. Harris AC, Young R, Devine S, Hogan WJ, Ayuk F, Bunworasate U. et al. International, Multicenter Standardization of Acute Graft-versus-Host Disease Clinical Data Collection: A Report from the Mount Sinai Acute GVHD International Consortium. Biol Blood Marrow Transpl. 2016;22:4-10. https://doi.org/10.1016/j. bbmt.2015.09.001.

13. Jagasia MH, Greinix HT, Arora M, Williams KM, Wolff D, Cowen EW, et al. National Institutes of Health Consensus Development Project on Criteria for Clinical Trials in Chronic Graft-versus-Host Disease: I. The 2014 Diagnosis and Staging Working Group Report. Biol Blood Marrow Transpl. 2015;21:389-401 e381. https://doi.org/ 10.1016/j.bbmt.2014.12.001.

14. Storb R, Gyurkocza B, Storer BE, Sorror ML, Blume K, Niederwieser D, et al. Graftversus-host disease and graft-versus-tumor effects after allogeneic hematopoietic cell transplantation. J Clin Oncol. 2013;31:1530-8. https://doi.org/10.1200/ JCO.2012.45.0247. 
15. Ljungman $P$, Boeckh $M$, Hirsch HH, Josephson F, Lundgren J, Nichols G. et al. Definitions of cytomegalovirus infection and disease in transplant patients for use in clinical trials. Clin Infect Dis. 2017;64:87-91. https://doi.org/10.1093/cid/ciw668.

16. Styczynski J, van der Velden W, Fox CP, Engelhard D, de la Camara R, Cordonnier C. et al. Management of Epstein-Barr Virus infections and post-transplant lymphoproliferative disorders in patients after allogeneic hematopoietic stem cell transplantation: Sixth European Conference on Infections in Leukemia (ECIL-6) guidelines. Haematologica. 2016;101:803-11. https://doi.org/10.3324/haematol.2016.144428.

17. Sorror ML, Maris MB, Storb R, Baron F, Sandmaier BM, Maloney DG, et al. Hematopoietic cell transplantation (HCT)-specific comorbidity index: a new tool for risk assessment before allogeneic HCT. Blood. 2005;106:2912-9.

18. Gratwohl A. The EBMT risk score. Bone Marrow Transpl. 2012;47:749-56. https://doi.org/10.1038/bmt.2011.110.

19. Armand P, Gibson CJ, Cutler C, Ho VT, Koreth J, Alyea EP. et al. A disease risk index for patients undergoing allogeneic stem cell transplantation. Blood. 2012;120:905-13. https://doi.org/10.1182/blood-2012-03-418202.

20. Shouval R, Fein JA, Labopin M, Kroger N, Duarte RF, Bader P, et al. Outcomes of allogeneic haematopoietic stem cell transplantation from HLA-matched and alternative donors: a European Society for Blood and Marrow Transplantation registry retrospective analysis. Lancet Haematol. 2019;6:e573-e584. https://doi.org/10.1016/ S2352-3026(19)30158-9.

21. Mehta RS, Holtan SG, Wang T, Hemmer MT, Spellman SR, Arora M, et al. GRFS and CRFS in alternative donor hematopoietic cell transplantation for pediatric patients with acute leukemia. Blood Adv. 2019;3:1441-9. https://doi.org/10.1182/ bloodadvances.2018030171.

22. Morishima Y, Kashiwase K, Matsuo K, Azuma F, Morishima S, Onizuka M, et al. Biological significance of HLA locus matching in unrelated donor bone marrow transplantation. Blood. 2015;125:1189-97. https://doi.org/10.1182/blood-2014-10-604785.

23. Soiffer RJ, Kim HT, McGuirk J, Horwitz ME, Johnston L, Patnaik MM, et al. Prospective, randomized, double-blind, phase III clinical trial of anti-T-lymphocyte globulin to assess impact on chronic graft-versus-host disease-free survival in patients undergoing HLA-matched unrelated myeloablative hematopoietic cell transplantation. J Clin Oncol. 2017. https://doi.org/10.1200/JCO.2017.75.8177

24. Admiraal R, Nierkens S, de Witte MA, Petersen EJ, Fleurke GJ, Verrest $L$, et al. Association between anti-thymocyte globulin exposure and survival outcomes in adult unrelated haemopoietic cell transplantation: a multicentre, retrospective, pharmacodynamic cohort analysis. Lancet Haematol. 2017;4:e183-e191. https://doi.org/10.1016/S2352-3026(17)30029-7.

25. Nagler A, Dholaria B, Labopin M, Socie G, Huynh A, Itala-Remes M, et al. The impact of anti-thymocyte globulin on the outcomes of patients with $A M L$ with or without measurable residual disease at the time of allogeneic hematopoietic cell transplantation. Leukemia. 2020;34:1144-53. https://doi.org/10.1038/s41375-019-0631-5.

26. Walker I, Panzarella T, Couban S, Couture F, Devins G, Elemary M, et al. Addition of anti-thymocyte globulin to standard graft-versus-host disease prophylaxis versus standard treatment alone in patients with haematological malignancies undergoing transplantation from unrelated donors: final analysis of a randomised, open-label, multicentre, phase 3 trial. Lancet Haematol. 2020;7:e100-e111. https://doi.org/10.1016/S2352-3026(19)30220-0.
27. Kroger N, Solano C, Wolschke C, Bandini G, Patriarca F, Pini M. et al. Antilymphocyte globulin for prevention of chronic graft-versus-host disease. N. Engl J Med. 2016;374:43-53. https://doi.org/10.1056/NEJMoa1506002.

28. Cutler C, Stevenson K, Kim HT, Richardson P, Ho VT, Linden E, et al. Sirolimus is associated with veno-occlusive disease of the liver after myeloablative allogeneic stem cell transplantation. Blood. 2008;112:4425-31. https://doi.org/10.1182/ blood-2008-07-169342.

29. Cutler C, Henry NL, Magee C, Li S, Kim HT, Alyea E, et al. Sirolimus and thrombotic microangiopathy after allogeneic hematopoietic stem cell transplantation. Biol Blood Marrow Transpl. 2005;11:551-7. https://doi.org/10.1016/j. bbmt.2005.04.007.

30. McCrea JB, Macha S, Adedoyin A, Marshall W, Menzel K, Cho CR, et al. Pharmacokinetic drug-drug interactions between letermovir and the immunosuppressants cyclosporine, tacrolimus, sirolimus, and mycophenolate mofetil. J Clin Pharm. 2019;59:1331-9. https://doi.org/10.1002/jcph.1423.

31. Battipaglia G, Labopin M, Kroger N, Vitek A, Afanasyev B, Hilgendorf I, et al. Posttransplant cyclophosphamide vs antithymocyte globulin in HLA-mismatched unrelated donor transplantation. Blood. 2019;134:892-9. https://doi.org/10.1182/ blood.2019000487.

\section{AUTHOR CONTRIBUTIONS}

WV, SD, GC, MW designed the study. WV, GC, MW collected patient, donor and HCT data. AM obtained and supervised data on HLA-typing. WV, SD, GC, MW, JK, AM, NB, $\mathrm{GH}$ analyzed and interpreted the data. $\mathrm{AH}, \mathrm{WV}$ performed the statistical analysis. WV, SD, GC, MW wrote the manuscript. All authors critically revised and approved the final manuscript.

\section{Compliance with ethical standards}

\section{CONFLICT OF INTEREST}

The authors declare no competing interests.

\section{ADDITIONAL INFORMATION}

Supplementary information The online version contains supplementary material available at https://doi.org/10.1038/s41409-021-01369-9.

Correspondence and requests for materials should be addressed to W.J.F.M.v.d.V.

Reprints and permission information is available at http://www.nature.com/ reprints

Publisher's note Springer Nature remains neutral with regard to jurisdictional claims in published maps and institutional affiliations. 